\title{
Observotório
}

ISSN n² 2447-4266

Vol. 1, no 1, Maio-Agosto. 2015

DOI: http://dx.doi.org/10.20873/uft.2447-4266.2015v1n1p12

\section{Editorial, ou à guisa de um começo...}

"Somos como anões aos ombros de gigantes, pois podemos ver mais coisas do que eles e mais distantes, não devido à acuidade da nossa vista ou à altura do nosso corpo, mas porque somos mantidos e elevados pela estatura de gigantes."

Bernardo de Chartres (Metalogicon, Liber Tertius, cap. IV)

Volume 1. Número 1. O início de uma caminhada. Esse é o número de abertura da Revista Observatório, publicado pelo Núcleo de Pesquisa e Extensão Observatório de Pesquisas Aplicadas ao Jornalismo e ao Ensino (OPAJE) da Universidade Federal do Tocantins (UFT).

Mas, mesmo sendo a 'abertura', não se trata de um começo, apenas. É o consolidar de uma caminhada realizada pelo OPAJE-UFT e seus pesquisadores desde sua criação em 2013, primeiro como Grupo de Pesquisa na plataforma dos Diretórios de Grupos de Pesquisa do CNPq, e, depois, em 2014, quando de sua aprovação como Núcleo de Pesquisa e Extensão pela própria universidade.

Desde sua criação, o OPAJE-UFT mantém parcerias produtivas com redes de pesquisa e de pesquisadores, primeiro com a UNESP, por meio do prof. Dr. Nelson Russo de Moraes e do grupo de pesquisa por ele coordenado, o Grupo de Pesquisa em Democracia e Gestão Social/UNESP-CNPq, que além das publicações e pesquisas conjuntas, partilha também a editoria deste periódico que ora se inicia; segundo, com a Rede Nacional de Observatórios de Imprensa, a RENOI, importante parceria para a consolidação do OPAJE na área de Jornalismo e Comunicação; e, terceiro, a Rede Internacional de Pesquisadores sobre Bolonha/International Researchers Network for 


\section{Observotório \\ ISSN n² 2447-4266 \\ Vol. 1, n 1, Maio-Agosto. 2015}

Bologna (REBOL), que conta com pesquisadores de 23 universidades: do Brasil: UFT, UNESP, UFPB, UNICAMP, UFBA, UFU, UEG, UEMT, USP, UTFPR, UNIOESTE; de Portugal: Universidade da Beira Interior, Instituto Politécnico de Viseu, Instituto Politécnico de Coimbra, Universidade Técnica de Lisboa, Universidade do Porto, Instituto Politécnico da Guarda, Universidade Trás-os-Montes e Alto Douro, e Universidade do Minho; da Espanha, Universidade de Valladolid; da Inglaterra: University College London; de Moçambique: Universidade Eduardo Mondlane; e de Cabo Verde: Universidade de Cabo Verde. Alguns desses também partilham a editoria deste periódico.

Talvez essa seja a marca mais importante da Revista Observatório: ela não é editada por um núcleo apenas, mas é a construção de redes de pesquisadores internacionalizada, que partilham a responsabilidade de criar um espaço de divulgação científica que agrega pesquisadores e editores de Brasil, Cabo Verde, Portugal e Moçambique.

Dessa forma, a Revista Observatório nasce como uma publicação quadrimestral, internacional, que tem como missão atuar na promoção da discussão acadêmica e de estudos interdisciplinares avançados no campo da Comunicação, do Jornalismo e da Educação. O propósito da Revista Observatório é constituir-se como um periódico acadêmico de referência a fim de apresentar, na forma de artigos científicos, resultados de pesquisas e estimular debates sobre questões teórico-metodológicas da pesquisa em Comunicação, Jornalismo e Educação, ao mesmo tempo em que se propõe a contribuir para a criação e fortalecimento de uma rede de pesquisadores na confluência dessas áreas em nível nacional e internacional, tendo por base os grupos e núcleos de pesquisa no Brasil e no Exterior. A revista se pauta no princípio da democratização do conhecimento científico incentivando o acesso público, imediato e livre a todo o seu conteúdo publicado.

Nesse número, de temas livres, aberto a debates em Comunicação, Jornalismo e Educação, contamos com olhares diversos sobre resultados de pesquisas e questões teórico-metodológicas dessa amálgama de três áreas em construção.

O primeiro artigo é intitulado A teoria e a prática do jornalismo investigativo: Uma análise das reportagens premiadas da Agência Pública, de Paula Melani Rocha e Mariana 


\section{Observatório \\ ISSN n² 2447-4266 \\ Vol. 1, n 1, Maio-Agosto. 2015}

Galvão Noronha. Nesse artigo as autoras propõem analisar os saberes teóricos e práticos que envolvem o jornalismo investigativo e sua prática no Brasil. A discussão analisa as quatro reportagens premiadas da Agência Pública em 2014, exclusivamente de autoria feminina.

O segundo artigo é intitulado Comunicólogo que brinca comunica mais?, de Ivany Câmara Neiva. Nesse artigo a autora trata da utilização de brinquedos e brincadeiras como recurso de aprendizagem no ensino superior dentro do Curso de Comunicação Social da Universidade Católica de Brasília.

O terceiro artigo é intitulado Jornais de internet simulam o papel, de Luciana Moherdaui. Nesse artigo a autora apresenta a pesquisa realizada em interfaces jornalísticas dos principais sites de jornais do Brasil e do mundo, apontando diretrizes para repensar a forma pela qual são exibidas as notícias na internet, especialmente nas redes sociais.

O quarto artigo vem de Moçambique, e é intitulado $O$ sucesso da inculturação do telemóvel nas comunidades moçambicanas e a sua múltipla funcionalidade social, de Celestino Vaz Joanguete. Nesse artigo o autor discute a empregabilidade do dispositivo móvel na monitoria de governação, no processo comunicativo, e nos processos de desenvolvimento do negócio e transações comerciais em Moçambique.

O quinto artigo é intitulado Lanterna Mágica: as Luzes no jornalismo de José Liberato (1813-1821), de Luís Francisco Munaro. Nesse artigo o autor investiga os ideais letrados de José Liberato, sua proposta pedagógica e, mais importante, como o seu exercício jornalístico construiu uma utopia voltada para pensar o futuro português.

O sexto artigo é intitulado Capacidade de Absorção do Conhecimento e a Comunicação com o Ambiente Externo: Uma Análise em Empresas de Palmas/TO, de Suzana Gilioli Nunes. Nesse artigo a autora avalia a capacidade de absorção do conhecimento organizacional, tendo como uma das suas dimensões a comunicação com o ambiente externo. Trata-se dos resultados de uma pesquisa de caráter quantitativo com cem empresas pertencentes aos setores de comércio e de serviços, localizadas na cidade de Palmas, TO. 


\section{Obsisto \\ Vol. 1, no 1, Maio-Agosto. 2015}

O sétimo artigo é intitulado $\mathrm{A}$ invisibilização identitária da África lusófona na Folha de S. Paulo e em O Globo, de Elton Antunes e José Cristian Góes. Nesse artigo os autores abordam como os jornais Folha de S. Paulo e O Globo noticiaram as relações entre Brasil e África portuguesa, com foco nas notícias nesses jornais no período de 1996 a 2006, quando a CPLP (Comunidade dos Países de Língua Portuguesa) fez dez anos de instituída.

O oitavo artigo é intitulado Reflexões sobre a cultura da imagem e o imaginário feminino na publicidade, de Verônica Dantas Meneses e Cynthia Mara Miranda. Nesse artigo as autoras refletem sobre a construção de práticas de consumo sobre a idealização da imagem feminina a partir da publicidade. Aspectos sobre corpos femininos erotizados e disciplinados e a mistificação da mulher, à luz da sociedade do consumo são problematizados.

O nono artigo é intitulado A Leitura e a Tela, de Sérgio Luiz Alves da Rocha. Nesse artigo o autor discute como professores e alunos entendem alguns temas relacionados às suas concepções e práticas de leitura, utilizando como recurso metodológico imagens produzidas pelos sujeitos da pesquisa. Diferentes concepções sobre a leitura, a relação entre a leitura literária e outros tipos de leitura e dessas com as "novas tecnologias", o papel da escola, motivando ou não o acesso aos diferentes suportes e textos, foram alguns dos tópicos discutidos no estudo.

O décimo artigo é intitulado Os sentidos nos ditos e nos não ditos pelas revistas Veja, Época, IstoÉ e CartaCapital sobre a posse da presidente Dilma Rousseff, de Daiane Bertasso, Sabrina Franzoni e Silvia Lisboa. Nesse artigo as autoras apontam para quais são os sentidos produzidos nos ditos e nos não ditos pelas revistas Veja, Época, IstoÉ e CartaCapital sobre a posse da presidente Dilma Rousseff. Com base na perspectiva teórico-metodológica da análise do discurso, identificam três formações discursivas predominantes nos ditos das quatro revistas: Posse controversa, Posse melancólica e Posse da dieta.

O décimo primeiro artigo é intitulado Cidade. City. Cité. Smartcity. O espaço contemporâneo do Período Técnico Científico Informacional. Duas experiências globais, de Paulo Celso Silva. Nesse artigo o autor apresneta duas experiências urbanas 


\section{Observatório \\ ISSN n² 2447-4266 \\ Vol. 1, n 1, Maio-Agosto. 2015}

conceitualmente diferentes, seja na maneira de criar e organizar o espaço ou no viver. Trata-se de Celebration uma cidade informacional com um projeto de oferecer ao consumidor-morador uma alternativa estética na união entre a tecnologia e a tradição. E, a outra, a cidade asiática, por seu turno, oferece o conceito de Smartcity de Songdo, onde a tecnologia não é oferecida em si-mesmo, mas, conectada à inteligência do morador.

Na seção ensaio, temos a reflexão no artigo intitulado Projeto múltiplos olhares: o exercício do documentário etnográfico na formação do jornalista, de Carlos Fernando Martins Franco. Nesse artigo o autor apresenta o relato de experiência inicial de um experimento que levou estudantes de jornalismo de diferentes períodos ao exercício de novas possibilidades de linguagem e incursão em olhares diversos, utilizando o documentário audiovisual etnográfico como ferramental.

E, por último, na seção resenha, temos a produção intitulada Construindo a memória e identidade no Tocantins, de João Nunes da Silva. Nessa resenha o autor apresenta obra publicada em 2015 que tem como título Memória e ldentidade, que trata do povoado que foi atingido pela construção de uma Usina Hidrelétrica, a Usina do Lajeado, em 2001 e os processos de construção da identidade.

Esperamos que esse número inicial contribua com os processos de formação e atualização dos que enveredarem por sua leitura, nos cursos de Comunicação Social, Educação e áreas correlatas.

Palmas, maio-agosto, 2015.

Editor Geral / Chief Editor / Editor general

Francisco Gilson Rebouças Porto Junior, Universidade Federal do Tocantins (UFT), Brasil Editores adjuntos nacionais / Associate Editors / Editores Asociados

João Nunes da Silva, Universidade Federal do Tocantins (UFT), Brasil Nelson Russo de Moraes, UNESP - Universidade Estadual Paulista Júlio de Mesquita Filho, Brasil

Editores adjuntos internacionais / Associate Editors / Editores Asociados Celestino Vaz Tomas Jone Joanguete, Universidade Eduardo Mondlane, Moçambique Elvira Gomes dos Reis, Universidade do Cabo Verde, Cabo Verde 


\section{Obevisto \\ ISSN n² 2447-4266 \\ Vol. 1, n 1, Maio-Agosto. 2015}

Luís António Martins Santos, Universidade do Minho, Portugal

Aceito em: 30/09/2015. Publicado em: 30.09.2015.

\section{Referências}

ANTUNES, E.; GÓES, J. C. A invisibilização identitária da África lusófona na Folha de S. Paulo e em O Globo. Revista Observatório, v. 1, n. 1, p. 147-170, 30 set. 2015.

BERTASSO, D.; FRANZONI, S.; LISBOA, S. Os sentidos nos ditos e nos não ditos pelas revistas Veja, Época, IstoÉ e CartaCapital sobre a posse da presidente Dilma Rousseff. Revista Observatório, v. 1, n. 1, p. 216-232, 30 set. 2015.

FRANCO, C. F. M. Projeto múltiplos olhares: o exercício do documentário etnográfico na formação do jornalista. Revista Observatório, v. 1, n. 1, p. 247-269, 30 set. 2015.

JOANGUETE, C. V. O sucesso da inculturação do telemóvel nas comunidades moçambicanas e a sua múltipla funcionalidade social. Revista Observatório, v. 1, n. 1, p. 87-102, 30 set. 2015.

MENESES, V. D.; MIRANDA, C. M. Reflexões sobre a cultura da imagem e o imaginário feminino na publicidade. Revista Observatório, v. 1, n. 1, p. 171-193, 30 set. 2015.

MOHERDAUI, L. Jornais de internet simulam o papel. Revista Observatório, v. 1, n. 1, p. 6386, 30 set. 2015.

MUNARO, L. F. Lanterna Mágica: as Luzes no jornalismo de José Liberato (1813 1821). Revista Observatório, v. 1, n. 1, p. 103-122, 30 set. 2015.

NEIVA, I. C.; AUGUSTO, A. Comunicólogo que brinca comunica mais?. Revista Observatório, v. 1, n. 1, p. 43-62, 30 set. 2015.

NUNES, S. G. Capacidade de Absorção do Conhecimento e a Comunicação com o Ambiente Externo: Uma Análise em Empresas de Palmas/TO. Revista Observatório, v. 1, n. 1, p. 123-146, 30 set. 2015.

ROCHA, P. M.; NORONHA, M. G. A teoria e a prática do jornalismo investigativo: Uma análise das reportagens premiadas da Agência Pública. Revista Observatório, v. 1, n. 1, p. 18-42, 30 set. 2015.

ROCHA, S. L. A. DA. A Leitura e a Tela. Revista Observatório, v. 1, n. 1, p. 194-215, 30 set. 2015.

SILVA, J. N. DA. Construindo a memória e identidade no Tocantins. Revista Observatório, v. 1, n. 1, p. 270-275, 30 set. 2015.

SILVA, P. C. Cidade. City. Cité. Smartcity. O espaço contemporâneo do Período Técnico Científico Informacional. Duas experiências globais. Revista Observatório, v. 1, n. 1, p. 233246, 30 set. 2015. 